\title{
"RECICLA GOSTOSO": O PAPEL DA EDUCAÇÃO AMBIENTAL NA COLETA SELETIVA EM SÃO MIGUEL DO GOSTOSO (RN)
}

Otomar Lopes Cardoso Junior ${ }^{1}$

Resumo: O lixo urbano é um grave problema, sobretudo para quem depende do turismo baseado na natureza. São Miguel do Gostoso é destino privilegiado no Rio Grande do Norte mas, a expansão da cidade (antes, pacata praia de pescadores) trouxe uma maior "produção" de lixo. Recentemente foi criada a Associação Recicla Gostoso (coleta seletiva) em busca de assegurar uma renda mínima para os catadores. Após um ano, no entanto, o resultado econômico é pífio, comprometendo sua viabilidade. Neste trabalho a ideia da Educação Ambiental é balizadora para que a atividade da Associação possa ser ampliada para benefício de todos e apresenta propostas concretas de rápida implementação que podem reverter, a curto-médio prazo, os resultados atuais.

Palavras-chave: Coleta Seletiva; Associação Gostoso Recicla; Educação Ambiental. 


\section{Introdução}

Lixo, como livrar-se daquilo que foi descartado justamente por ter sido considerado... "lixo"?

Este é um dos dilemas da atual sociedade visto o crescente perfil de consumo atual, seja em função do excesso - o consumismo - seja em função do acesso cada vez mais facilitado às diferentes categorias sociais. Um problema, aliás, que não é apenas constante nas sociedades economicamente mais avançadas, como também em países com marcantes disparidades socioeconômicas, como é o caso do Brasil.

O problema associado ao lixo urbano é seu impacto ambiental afinal, "um dos maiores desafios com que se defronta a sociedade moderna é o equacionamento da geração excessiva e da disposição final ambientalmente segura dos resíduos sólidos" (JACOBI; BESEN, 2011, p. 135) Esta premissa é validada nos grandes centros urbanos nacionais como também em todas as cidades de médio porte, tendo avançado ao longo dos últimos anos para todas as demais, inclusive aquelas com menor impacto populacional: na verdade, a concentração urbana, ainda que reduzida (distritos ou bairros distantes das sedes ou das áreas centrais) ou até mesmo pendular (as praias, na época das férias escolares, feriados e finais de semana "prolongados"), esbarram na dificuldade de apresentar uma melhor destinação ao lixo produzido continuamente.

Embora seja apenas um dos aspectos dos atuais problemas sociais das cidades, há de se destacar a amplitude de seu impacto seja na paisagem (lixo espalhado pelas ruas), sensorial (odores) e em políticas públicas de saúde (doenças e epidemias) ou econômicas (solos degradados, erosão etc). Tornase, portanto, necessária uma proposta de melhoria desta condição ambiental:

Segundo o Urban World Forum (2002), a sustentabilidade urbana pode ser definida a partir de um conjunto de prioridades, tais como a superação da pobreza, a promoção da equidade, a melhoria das condições ambientais e a prevenção da sua degradação (JACOBI; BESEN, 2011, p. 135)

Mas, o que é lixo?

O lixo, por definição, é todo e qualquer resíduo proveniente das atividades humanas ou geradas pela natureza em aglomerações urbanas. No dicionário, ela é definida como sujeira, imundice, coisa ou coisas inúteis, velhas, sem valor. Lixo, na linguagem técnica, é sinônimo de resíduos sólidos e é representado por materiais descartados pelas atividades humanas. (SOUZA SILVA et al, 2015, p. 66) 
Atualmente esta versão ultrapassada dos dicionários cede espaço à uma visão mais dinâmica e compreendida como uma realidade que não pode ser observada apenas como uma hipótese, um dado ou uma realidade fática, mas como uma possibilidade de mudança de paradigma social que deve ser enfrentada por todos os atores em qualquer cidade ou localidade, embora haja algumas vezes tendências a responsabilizar a administração pública como uma responsável único ou principal pelo problema e, mais grave, única responsável pela solução:

\begin{abstract}
A administração pública municipal tem a responsabilidade de gerenciar os resíduos sólidos, desde a sua coleta até a sua disposição final, que deve ser ambientalmente segura. O lixo produzido e não coletado é disposto de maneira irregular nas ruas, em rios, córregos e terrenos vazios, e tem efeitos tais como assoreamento de rios e córregos, entupimento de bueiros com consequente aumento de enchentes nas épocas de chuva, além da destruição de áreas verdes, mau cheiro, proliferação de moscas, baratas e ratos, todos com graves consequências diretas ou indiretas para a saúde pública. (JACOBI; BESEN, 2011, p. 136)
\end{abstract}

De forma mais incisiva, a partir da Conferência de Estocolmo, promovida pela Onu em 1972, a questão ambiental nasce como uma iniciativa coletiva necessária para um problema também de ordem coletiva. Em pleno século XXI, no entanto, as muitas discussões ambientais ainda estão centralizadas em alguns tópicos, tais o lixo urbano. As políticas nacionais, com suas legislações aperfeiçoadas ao longo dos últimos anos, demonstram que "ainda se encontra muito aquém dos patamares necessários para efetivamente reduzir a quantidade de resíduos potencialmente recicláveis que ainda são dispostos em aterros ou lixões" (JACOBI; BESEN, 2011, p. 142). E continuam os autores a afirmar que, "cabe destacar que as primeiras iniciativas no Brasil datam de 1989" (p. 142), embora os legados jurídicos mais consistentes são bem mais recentes:

- Lei de Saneamento Básico (Lei 11.445/2007);

- Lei dos Consórcios Públicos (Lei 11.107/1995) e seu Decreto regulamentador (Decreto 6.017/2007); e

- Lei da Política Nacional de Resíduos Sólidos (Lei 12.305/2010) e seu Decreto regulamentador (Decreto $7.404 / 2010)$.

\title{
A Educação Ambiental e o projeto de pesquisa aplicado
}

A Educação Ambiental pode ser promovida e realizada em seus aspectos formais e não-formais. Neste projeto de pesquisa as duas formatações estão devidamente inseridas, seja inicialmente como projeto de extensão da disciplina Educação Ambiental, obrigatória para os alunos de Geografia (Licenciatura) da UFRN, seja na proposta de intervenção pretendida 
a partir de ação de enfretamento ao (ou redução do) problema do lixo urbano pouco aproveitado.

Para Castro e Pereira (2016, p. 112),

no que diz respeito à inserção da Educação Ambiental nas disciplinas, a pesquisa desenvolvida por Loureiro (2007) também identificou que a maior preocupação/responsabilidade em abordá-la fica a encargo dos professores de Ciências e de Geografia.

De fato, a Geografia tem ampliado suas áreas de atuação e incorporado a questão ambiental como um dos aspectos relevantes para compreensão dos fenômenos sociais na ocupação do espaço, seja abordando questões técnicas (redução no uso de recursos naturais), econômicas (custo de produção e das matérias-primas naturais), educacionais (conscientização, desde cedo, das ações de cada indivíduo) e políticas (papel dos atores públicos e políticas públicas).

Da Educação Ambiental formal à não-formal há várias opções de união de esforços conjuntos para um resultado também comum, da qualidade de vida atual e futura. Por isto,

não se pode negar que, em geral, há muito empenho, por parte dos professores, em implementar ações em Educação Ambiental, e o maior destaque que a temática reciclagem acaba ganhando dentre as abordagens escolhidas, possivelmente pode estar associada ao destaque a ela conferido nas mídias, ou à maior familiaridade dos docentes com o assunto, ou a maior facilidade de contextualização que ela oferece. (CASTRO; PEREIRA, 2016, p. 113)

Não se deve restringir apenas ao poder da mídia ou à familiaridade dos docentes visto que:

Graças ao aumento do interesse pelas questões ambientais e aos recentes avanços tecnológicos e científicos, conhece-se mais sobre os problemas ambientais do que se conhecia no passado. Isso, porém, não tem sido suficiente para deter 0 processo de degradação ambiental em curso (MARCATTO, 2002, p. 8)

A ampliação dos conhecimentos técnicos e a facilidade do acesso à educação formal no Brasil bem como o crescimento da utilização de todo instrumental oferecido a partir da aceleração da comunicação (internet, redes sociais, aplicativos etc.) corrobora o pensamento do autor sobre o "interesse pelas questões ambientais", antes consideradas pouco impactantes ou muito 
distantes. É o que reforça Jacobi:

As políticas ambientais e os programas educativos relacionados à conscientização da crise ambiental demandam cada vez mais novos enfoques integradores de uma realidade contraditória e geradora de desigualdades, que transcendem a mera aplicação dos conhecimentos científicos e tecnológicos disponíveis. (JACOBI, 2003, p. 196)

Uma das possibilidades de conscientização a partir da intervenção concreta é o projeto realizado pela Associação Gostoso Recicla, organização social na cidade de São Miguel do Gostoso, especializada em coleta seletiva para reciclagem, para a qual novas ideias serão sugeridas no intuito de incrementar a participação popular - o exercício da cidadania - e o papel do poder público - parceria com a Prefeitura - tendo como tônica central os efeitos práticos da Educação Ambiental.

\section{Resíduos sólidos}

Os recursos naturais são finitos, mas são, ao mesmo tempo, necessários para a sobrevivência e perpetuação do ser humano no Planeta. Embora a sobrevivência possa ter sido um aprendizado inato ao indivíduo, desde seu surgimento, como forma de competição com outras espécies animais e no enfrentamento das adversidades climáticas, o crescimento desestruturado de consumo "da natureza" pode ser datado a partir da Revolução Industrial quando a intensidade do trabalho realizado por máquinas permitiu uma maior produção de alimentos e bens de consumo. Mais recentemente, no pós-II Guerra Mundial, os efeitos de um ávido mercado consumidor tornaram-se cada vez mais visíveis em todas as regiões do Planeta embora, em escalas diferentes em função das desigualdades na distribuição das riquezas.

A conferência Rio-92 foi um dos anteparos à ausência de preocupação com a renovação da natureza, nas condições de consumo da época, e com o desenvolvimento sustentável que se tornava uma premissa básico para os líderes dos países reunidos na emblemática conferência da Onu no Rio de Janeiro.

O bem-estar global baseado em recursos da natureza são, desde então, representados não somente pelo seu custo de extração ou obtenção, mas, mais grave, pelo seu custo de preservação, de reposição e, em alguns casos, de impossibilidade de recuperação. Entendia-se, 
conforme Randall et al. (1974), os recursos naturais geram diversos bens e serviços que contribuem para o bem-estar geral dos indivíduos. Alguns desses benefícios podem ser valorados por estarem relacionados com o sistema de mercado, como produção de alimentos e minérios (RODRIGUES; SANTANA, 2012, p. 302)

A "precificação" do meio ambiente tomou forma de uma questão coletiva com uma percepção crescente de que as ações imediatas trazem impactos imediatos, mas também a médio e longo prazos. A conscientização de que a poluição afeta a todos ainda supera a ideia de que a ação individual ou individualizada, se repetida por grande parcela da população, terá um resultado benéfico bem mais amplo do que o gesto simbólico tal, por exemplo, a separação do lixo doméstico para fins de reciclagem: as atitudes de uma unidade familiar não geram um impacto expressivo mas é o somatório destas atitudes, muitas vezes sem a necessidade de uma coordenação ou gestão hierarquizada, que modificará o cenário futuro. Nesta percepção,

as sociedades são as principais causadoras de um dos maiores problemas que circulam o meio ambiente, que são a poluição do ar, solo, alimentos por meio do lixo e as consequências pelo simples fato de não separarem e reciclarem de forma contundente e por não possuírem a visão de que esses problemas podem afetar e vão afetar as futuras gerações (SOUZA SILVA et al, 2015, p. 64)

A Educação Ambiental - formal e não-formal - têm esta perspectiva de trabalhar a problemática destas "consequências" mencionadas, contribuindo para a criação desta "visão" mais ampla dos problemas. E uma das ações geradoras de mudanças pode vir da reciclagem, um dos formatos que se apresenta "sustentável economicamente":

Reduzir a geração de resíduos sólidos demanda respostas urgentes que implicam em mudanças dos padrões existentes de produção e consumo da sociedade moderna e a implantação de um gerenciamento integrado, sustentável economicamente, socialmente justo e ambientalmente eficiente (BESEN, 2011, p. 20).

Cada cidade/comunidade terá seus resíduos sólidos de acordo com as características sociais de moradia, serviços presentes para a população e atividades econômico-produtivas em sua extensão territorial. Há, portanto, uma diversidade de resíduos sólidos que não estão presentes em igualdade de situações; como demonstram Jacobi e Bensen (2011, p. 138) na classificação a Revbea, São Paulo, V. 14, № 1: 295-315, 2019. 
seguir, é possível atribuir as "fontes geradoras" e os responsáveis pela redução dos impactos ambientais bem como uma das possibilidades de "tratamento e disposição final" (Quadro 1):

Quadro 1 - Características dos resíduos sólidos e da sua gestào

\begin{tabular}{|c|c|c|c|c|}
\hline $\begin{array}{l}\text { Residuos } \\
\text { sólidos }\end{array}$ & $\begin{array}{l}\text { Fontes } \\
\text { geradoras }\end{array}$ & Residuos produzidos & Responsãvel & $\begin{array}{l}\text { Tratamento e } \\
\text { disposiçāo final }\end{array}$ \\
\hline $\begin{array}{l}\text { Domiciliar } \\
\text { (RSD) }\end{array}$ & $\begin{array}{l}\text { Residencias. } \\
\text { edificios. } \\
\text { empreas. } \\
\text { escolas. }\end{array}$ & $\begin{array}{l}\text { Sobras de alimentos, } \\
\text { produtos deteriorados, lixo } \\
\text { de banheiro embalagens } \\
\text { de papel, vidro, metal. } \\
\text { plastico, isopor, longa } \\
\text { vida, pilhas, eletrōnicos } \\
\text { baterias, fraldas e outros }\end{array}$ & Municipio & $\begin{array}{l}\text { 1. Aterro sanitário } \\
\text { 2. Central de } \\
\text { triagem de } \\
\text { reciclăveia } \\
\text { 3. Central de } \\
\text { compostagem } \\
\text { 4. Lixăo } \\
\end{array}$ \\
\hline $\begin{array}{l}\text { Comercial } \\
\text { Pequeno } \\
\text { gerador }\end{array}$ & $\begin{array}{l}\text { Comercios. } \\
\text { bares. } \\
\text { restaurantes. } \\
\text { empresas }\end{array}$ & $\begin{array}{l}\text { Embalagens de papel } \\
\text { eplástico. sobras de } \\
\text { alimentos } \theta \text { outros }\end{array}$ & $\begin{array}{l}\text { Municipio } \\
\text { define a } \\
\text { quantidade }\end{array}$ & $\begin{array}{l}\text { 1. Aterro sanitário } \\
\text { 2. Central de } \\
\text { triagem da coleta } \\
\text { seletiva. } \\
\text { 3. Lixāo }\end{array}$ \\
\hline $\begin{array}{l}\text { Grande } \\
\text { gerador } \\
\text { (maior } \\
\text { volume) }\end{array}$ & $\begin{array}{l}\text { Comercios. } \\
\text { bares, } \\
\text { restaurantes. } \\
\text { empresas }\end{array}$ & $\begin{array}{l}\text { Embalagens de papel } \\
\text { eplástico, sobras de } \\
\text { alimentos } \Theta \text { outros }\end{array}$ & Gerador & $\begin{array}{l}\text { 1. Aterro sanitário } \\
\text { 2. Central de } \\
\text { triagem de } \\
\text { reciclăveis } \\
\text { 3. Lixāo } \\
\end{array}$ \\
\hline Público & $\begin{array}{l}\text { Varriçāo } \theta \\
\text { poda }\end{array}$ & $\begin{array}{l}\text { Poeira, follhas, papeis } \\
\text { e outros }\end{array}$ & Municipio & $\begin{array}{l}\text { 1. Aterro sanitário } \\
\text { 2. Central } \\
\text { de Compostagem } \\
\text { 3. Lixāo }\end{array}$ \\
\hline $\begin{array}{l}\text { Serviços } \\
\text { de agúde } \\
\text { (RSS) }\end{array}$ & $\begin{array}{l}\text { Hospitais. } \\
\text { clinicas. } \\
\text { consultórios. } \\
\text { laboratórios. } \\
\text { outros }\end{array}$ & 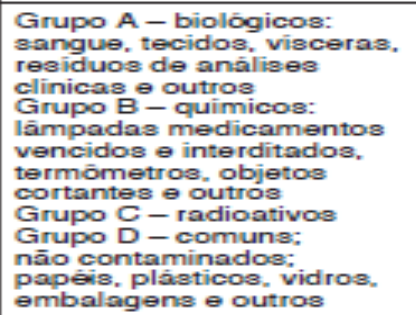 & $\begin{array}{l}\text { Municipio } \\
\ominus \\
\text { gerador }\end{array}$ & $\begin{array}{l}\text { 1. Incineraçāo } \\
\text { 2. Lixāo } \\
\text { 3. Aterro sanitärio } \\
\text { 4. Vala sêptica } \\
\text { 5. Micro-ondlas } \\
\text { 6. Autoclave } \\
\text { 7. Central de triagem } \\
\text { de recicláveis }\end{array}$ \\
\hline Industrial & Industrial & $\begin{array}{l}\text { Cinzas, lodos, oleos, } \\
\text { residuos alcalinos ou } \\
\text { acidos, plasticos, papel, } \\
\text { madeira, fibras, escorias } \\
\text { e outros }\end{array}$ & Gerador & $\begin{array}{l}\text { 1. Aterro industrial } \\
\text { 2. Lixăo }\end{array}$ \\
\hline $\begin{array}{l}\text { Portos. } \\
\text { aeroportos. } \\
\text { terminais }\end{array}$ & $\begin{array}{l}\text { Portos, } \\
\text { aeroportos. } \\
\text { terminais }\end{array}$ & $\begin{array}{l}\text { Residuos sépticos, sobras } \\
\text { de alimentos, material de } \\
\text { higiene } \theta \text { asseio pessoal } \\
\text { eutros }\end{array}$ & Gerador & $\begin{array}{l}\text { 1. Incineraçāo } \\
\text { 2. Aterro aanitário } \\
\text { 3. Lixāo }\end{array}$ \\
\hline Agricola & Agricultura & $\begin{array}{l}\text { Embalagens de } \\
\text { agrotóxicos, pneuse óleos } \\
\text { usados, embalagens } \\
\text { de medicamentos } \\
\text { veterinarios, plästicos } \\
\text { e outros }\end{array}$ & Gerador & $\begin{array}{l}\text { Central de } \\
\text { embalagens vazias } \\
\text { do Inpevs }\end{array}$ \\
\hline $\begin{array}{l}\text { Construçāo } \\
\text { civil (ACC) }\end{array}$ & $\begin{array}{l}\text { Obras } \theta \\
\text { reformas } \\
\text { residenciais e } \\
\text { comerciais }\end{array}$ & $\begin{array}{l}\text { Madeira, cimento, blocos, } \\
\text { pregos, gesao, tinta, latas. } \\
\text { ceramicas, pedra, areia } \\
\text { e outros. }\end{array}$ & $\begin{array}{l}\text { Gerador } \\
\text { Municipio } \\
\text { e gerador } \\
\text { pequeno } \\
\text { e grande }\end{array}$ & $\begin{array}{l}\text { 1. Ecoponto } \\
\text { 2. Arrea de } \\
\text { transbordo } \\
\text { e triagem (ATT) } \\
\text { 3. Area de } \\
\text { reciclagem } \\
\text { 4. Aterro de RCC } \\
\text { 5. Lixōes }\end{array}$ \\
\hline
\end{tabular}

Quadro 1: Características dos resíduos sólidos e sua gestão.

Fonte: Jacobi e Bensen (2011).

Para o Ministério do Meio Ambiente, para a Política Nacional de Resíduos Sólidos", há uma "responsabilidade compartilhada pelo ciclo de vida dos produtos", assim definida:

Revbea, São Paulo, V. 14, № 1: 295-315, 2019. 
conjunto de atribuições dos fabricantes, importadores, distribuidores e comerciantes, dos consumidores e dos titulares dos serviços públicos de limpeza urbana e manejo dos resíduos sólidos pela minimização do volume de resíduos sólidos e rejeitos gerados, bem como pela redução dos impactos causados à saúde humana e à qualidade ambiental decorrentes do ciclo de vida dos produtos, nos termos desta Lei (BRASIL, 2010).

Uma responsabilidade que incluiu outro importante ator neste contexto de produção-descarte, ainda não presente quando do início das discussões sobre desenvolvimento sustentável: o responsável pela coleta seletiva, primeiro passo para o aproveitamento de alguns resíduos sólidos para a reciclagem.

De acordo com a Política Nacional de Resíduos Sólidos, a implantação da coleta seletiva é obrigação dos municípios e metas referentes à coleta seletiva fazem parte do conteúdo mínimo que deve constar nos planos de gestão integrada de resíduos sólidos dos municípios (BRASIL, 2010)

Para o Ministério do Meio Ambiente, foi somente em 2011 que foi realizado um dos principais eventos nacionais de valorização da atividade de reciclagem e o reconhecimento do papel dos catadores quando, na Capital Federal, ocorreu o $1^{\circ}$ Congresso Nacional dos Catadores de Materiais Recicláveis, com cerca de 1.600 congressistas. Em outras ações que embasaram a abordagem jurídica e a confirmação da política pública nacional, destaca-se o Decreto 7.404/2010, que instituiu o "Comitê interministerial da Política Nacional de Resíduos Sólidos", coordenado pelo Ministério do Meio Ambiente que, entre outras competências, traz "formular estratégia para a promoção e difusão de tecnologias limpas para a gestão e o gerenciamento de resíduos sólidos" e "incentivar a pesquisa e o desenvolvimento nas atividades de reciclagem, reaproveitamento e tratamento dos resíduos sólidos". $\mathrm{Na}$ mesma data, em 23/12/2010, o Decreto 7.405 estabeleceu a denominação do "Comitê interministerial para inclusão social e econômica de catadores de materiais reutilizáveis", coordenado pela Secretaria-Geral da Presidência da República (com a participação de diferentes órgãos da administração direta, como também da indireta) e criou o programa intitulado Pró-Catador:

com a finalidade de integrar e articular as ações do Governo Federal voltadas ao apoio e ao fomento à organização produtiva dos catadores de materiais reutilizáveis e recicláveis, à melhoria das condições de trabalho, à ampliação das oportunidades de inclusão social e econômica e à expansão da coleta seletiva de resíduos sólidos, da reutilização e da reciclagem por meio da atuação desse segmento (BRASIL, 2010). 
A partir de então, reforça-se cada vez mais a proposta da coleta seletiva, uma:

coleta diferenciada de resíduos que foram previamente separados segundo a sua constituição ou composição. Ou seja, resíduos com características similares são selecionados pelo gerador (que pode ser o cidadão, uma empresa ou outra instituição) e disponibilizados para a coleta separadamente (BRASIL, 2010).

Uma coleta que se encontra hoje associada à diferentes organizações espalhadas em diferentes cidades do Brasil e organizadas, principalmente, sob a forma jurídica de cooperativas. A prática regular das atividades e a expansão econômica e financeira dos valores coletados trouxe a necessidade de formalização (com a instituição de um CNPJ) para que as associações ou cooperativas pudessem ter acesso à linhas de crédito e recursos originários de acordos de cooperação (parcerias, convênios etc.) com órgãos públicos mas, principalmente, em função da regularização tributária com a emissão de notas fiscais de venda dos produtos reciclados para os distribuidores de médiogrande porte e para as empresas que beneficiariam os produtos da coleta.

Esta visibilidade das associações ou cooperativas é apresentada por Mello et al. (2015, p.185) ao afirmar que "uma das formas de cooperativa mais conhecidas são as cooperativas de reciclagem", quando complementa a ideia de que:

As cooperativas se configuram como um empreendimento econômico solidário. Em face aos desafios para a sua sustentabilidade, as cooperativas enfrentam dificuldades parecidas com qualquer outro tipo de organização, em relação a governança e gestão capaz de se adaptarem às contingências do meio que a organização atua (...).

A caracterização enquanto "empreendimento econômico" traz consigo a ideia de que a sobrevivência da cooperativa passa, obrigatoriamente, pelas regras de mercado, uma receita maior do que a despesa para que, minimamente, possam ser honrados os compromissos básicos, tais salários, energia, água, material de consumo, combustível, manutenção dos veículos etc. Por isto, o papel do poder público, sobretudo municipal (pois a coleta e o tratamento do lixo são obrigações de cada prefeitura), é um dos fatores impulsionadores da proposta de criação de uma cooperativa de reciclagem.

A formação de patrimônio nos estágios iniciais das cooperativas de reciclagem é um processo que depende de parceria com organizações públicas, privadas e do terceiro setor. As parcerias, em muitos casos, permitem a aquisição de 
estrutura e infraestrutura básica para que as cooperativas possam iniciar suas atividades. Uma etapa importante é de capacitação do quadro de cooperados para realização do processo de compra de bens patrimoniais e dos mecanismos de controle desses bens (MELLO et al, 2015, p. 183)

A dinâmica da coleta seletiva exige, muitas vezes em função da extensão da cidade, da área de abrangência da cooperativa e do material a ser coletado, a utilização de carrinhos, carroças, veículos utilitários simples e até mesmo caminhões. Um esforço financeiro-econômico que nem sempre está presente na formalização das associações ou das cooperativas. Em outras situações, também em função da localização (área isolada ou espaço urbano domiciliar concentrado), grandes espaços livres e/ou a construção de galpões é que poderão viabilizar a atividade idealizada.

A "formação do patrimônio" passa a ser, em alguns casos, o principal aspecto para início das atividades de coleta seletiva em maior extensão e contará, geralmente, com a participação das prefeituras, sindicatos de trabalhadores ou entidades do terceiro setor, inclusive com recursos oriundos do exterior. Algumas associações ou cooperativas podem ser incentivadas diretamente por grandes empresas interessadas no volume de material reciclado a ser coletado ou com interesse em fomentar alguma atividade que contribua, efetivamente, para a preservação do meio ambiente ou, ainda, disponibilizando apoio financeiro revestido sob a forma de marketing social como forma de estampar para clientes e fornecedores sua participação em atividades beneficentes, sem interesse lucrativo direto.

Já para os líderes das cooperativas de reciclagem, a abordagem pode ser outra, baseada em uma proposta mais idealista de um projeto de desenvolvimento econômico e social apoiado - algumas vezes, amparado em um outro formato em relação ao meio ambiente, sua preservação: "De forma geral, expõe Gutberlet (2012), as cooperativas de reciclagem iniciam seus trabalhos a partir de perspectivas para servir um modelo de desenvolvimento capaz de suprir as necessidades econômicas do trabalhador e também preservar o meio ambiente" (CARDOZO et al. 2017).

Mas, independentemente das perspectivas dos atores envolvidos e interessados na formação de cooperativas de reciclagem há um aspecto em comum quando trata-se de coleta seletivo de lixo urbano: a centralidade do problema é percebida muito mais rapidamente e efetivamente a partir do contexto do município, ou da localidade.

Os problemas ambientais se manifestam em nível local. Em muitos casos, os residentes de um determinado local são, ao mesmo tempo, causadores e vítimas de parte dos problemas ambientais. [...]. Convivem diariamente com o problema e são, provavelmente, os maiores interessa os em resolvê-los. (MARCATTO, 2002, p. 12)

Revbea, São Paulo, V. 14, № 1: 295-315, 2019. 
A ideia do pertencimento ao mesmo espaço urbano imediato, de circulação contínua com a proximidade dos efeitos diretos do lixo urbano, tem produzido uma conscientização mais efetiva, ainda que haja muitos avanços indispensáveis à uma efetiva proteção do meio ambiente enquanto ação de cidadania. Mas, efetivamente, como ressalta Marcatto (2002), a convivência diária com mais este problema urbano, o lixo, é um dos fatores impulsionadores de novas ações em favor da coleta seletiva, da reciclagem e da redução de consumo de produtos (incluindo as embalagens) com menor impacto ambiental, "convivem diariamente com o problema", reforça o autor, entendem que a solução também parte de ações diretas de cada indivíduo.

\section{A Associação Gostoso Recicla}

A Associação Gostoso Recicla (Figura 1), criada recentemente, em 2017, partiu de uma dupla preocupação: a coleta-destinação do lixo e, principalmente, a possibilidade de auferir renda para os participantes da nova atividade.

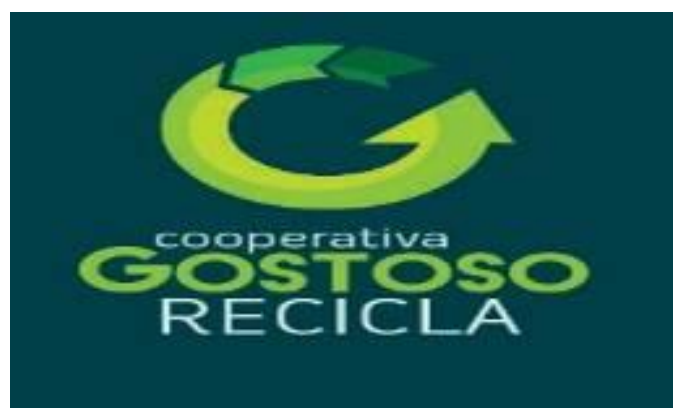

Figura 1: Identificação visual da Associação Gostoso Recicla.

Fonte: André (2016).

São Miguel do Gostoso era apenas mais uma localidade do Rio Grande do Norte conhecida por sua economia simplificada, dividida entre a agricultura e a pesca artesanal. A partir dos anos 1980, uma nova economia tem impulsionado a dinâmica do centro urbano e de suas praias, o turismo. Valorizado por suas belezas naturais e condições diferenciadas para a prática de atividades náuticas dependente de ventos fortes, além de um cenário mais pacato, diferente de outras praias com maior ocupação imobiliária (prédios, grandes hotéis, comércios etc), Gostoso - como é mais conhecido - foi aos poucos beneficiando-se do resultado da circulação de riqueza com a prestação de serviços aos turistas; afinal "o turismo é responsável por uma das principais receitas do Estado do RN. Gera mais de 100 mil empregos e possui outras 54 atividades atreladas a si direta ou indiretamente" (ABIH-RN).

Em 2017 teve o reconhecimento do Ministério do Turismo na nova classificação dos diversos municípios do País em função do "tamanho da economia turística": 
O Rio Grande do Norte teve 75 cidades agrupadas em categorias de A até $E$. Natal, assim como todas as capitais brasileiras, ficou na categoria $A$, que representa os municípios com maior fluxo turístico e maior número de empregos e estabelecimentos no setor de hospedagem. Outros dois municípios do estado, Mossoró e Tibau do Sul, foram inseridos na categoria B; e 10 na categoria C, incluindo São Miguel do Gostoso e Parnamirim. As 62 cidades restantes foram categorizadas como D e E.

$\mathrm{Na}$ última década, de forma mais intensa, a paisagem de algumas cidades do Rio Grande do Norte vêm sendo modificada com a expansão das torres de energia eólica nos chamados "parques eólicos", atraindo inclusive investimentos estrangeiros, como é o exemplo atual da empresa francesa Voltalia, enaltecida pelo Consulado Geral da França, em Recife: "O Nordeste do Brasil e, principalmente o Rio Grande do Norte, possui um enorme potêncial" visto que "dispõe de uma oportunidade única de desenvolvimento econômico e social. O estado conta, atualmente, com a maior capacidade de produção eólica do Brasil (...)". No entanto, o turismo ainda é a atividade mais efetiva em São Miguel do Gostoso, já valorizado nacionalmente.

Em 2006, definitivamente, conquistou um lugar de grande destaque na mídia nacional que ainda continua. Com um perfil definido de turismo de lazer, sem o agito e voltado para os esportes náuticos, a Revista Veja escolheu esta praia como o melhor "Novo Destino" do litoral norte baseado nas belezas do local, no fluxo de investimentos e nas taxas de crescimento do movimento de turistas (PORTAL SÃO MIGUEL DO GOSTOSO)

A intensificação do turismo com a explosão de pousadas e hotéis de pequeno porte distribuídos no litoral, na rua principal da sede de Gostoso mas também em áreas menos centrais do fluxo de maior circulação dos turistas, modificou o cenário e o desafio para a municipalidade: se antes o lixo urbano era restrito ao resultado do consumo da população local (consumo alicerçado na pesca e agricultura locais), com o crescente número de turistas "de um dia" ou de maior temporada, o volume de consumo, e portanto do lixo, teve uma rápida elevação impactando na demanda de serviços públicos mais eficientes para evitar a degradação do espaço, incluindo as praias, justamente um dos atrativos identificados pelos turistas.

Esta alteração no perfil do consumo foi percebida como uma fonte de renda passível de ser aproveitada a partir da coleta seletiva e da reciclagem criando, assim, um dos pilares que fundamentou a criação da Associação Gostoso Recicla.

A Associação (também autodenominada e mais conhecida como 
"cooperativa") foi idealizada por duas mulheres da cidade, Raimunda Veiga (ou "Rai") e Luziane Ferreira tendo sido criada com o objetivo "reduzir os resíduos e transformá-los em material reciclável gerando renda aos coletores da associação" (PALADAR). Desta forma, complementada a preocupação com a preservação ambiental com a possibilidade de nova fonte de renda para o pequeno grupo de associados (Figuras 2 e 3 ).
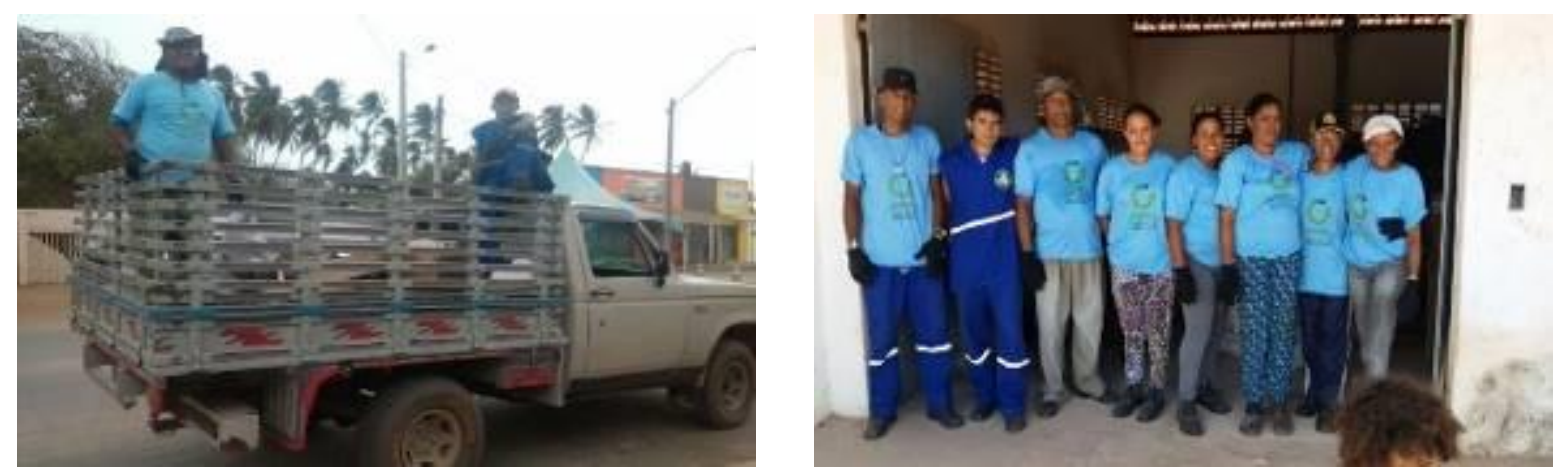

Figuras 2 e 3. Caminhão da Associação Gostoso Recicla para recolhimento do material reciclado. Equipe de coleta e triagem da Associação Gostoso Recicla. Fonte: André (2016).

Como já mencionado, a partir de Mello et al. (2015) a formação do patrimônio nos estágios iniciais também foi um dos marcos essenciais para o início das atividades, situação comum em diversas cooperativas e associações e que foi solucionada localmente com o apoio do Comdris-Conselho Municipal de Desenvolvimento Rural Integrado Sustentável e Solidário "que cedeu o espaço para instalação da associação, a antiga casa de farinha da cidade" (PALADAR, 2018) (Figuras 4 e 5).
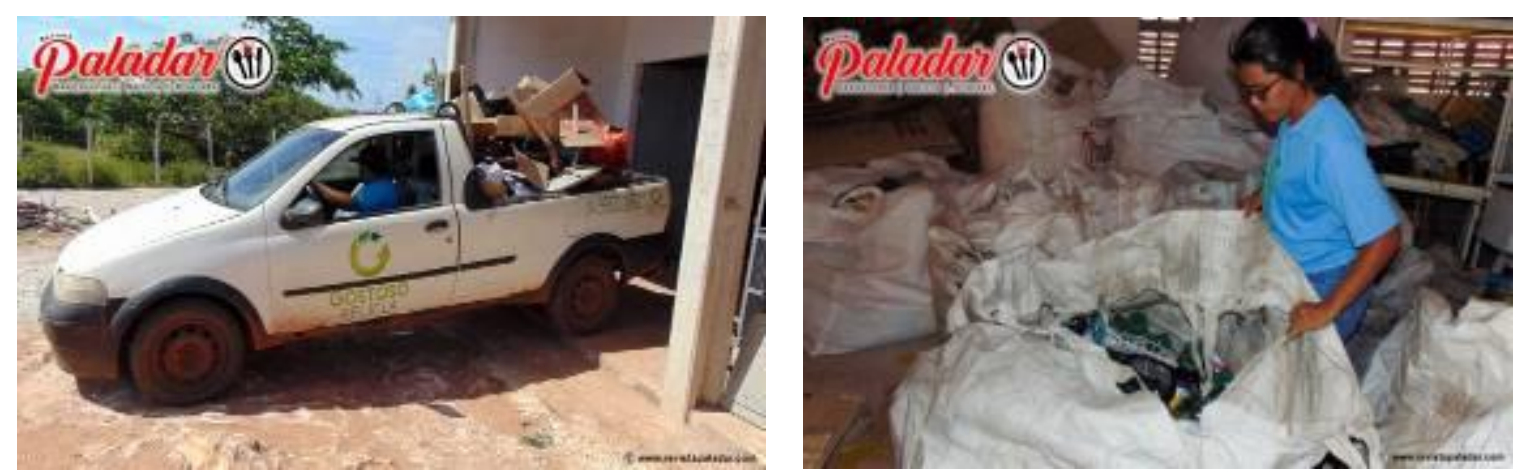

Figuras 4 e 5. Atividades no galpão: recebimento de material e triagem para a comercialização do material a ser reciclado. Fonte: Paladar (2018).

Aos poucos a Associação busca firmar-se como alternativa econômica autossustentável investindo em divulgação de suas atividades e o apelo social, mas também, indiretamente, promovendo o conceito de Educação Ambiental 
ao disseminar a ideia de participação individual-coletiva e de responsabilização das ações de cada cidadão. A própria apresentação da Associação em sua página do Facebook, embora curta, resume bem estes propósitos:

Somos a Associação Gostoso Recicla e o nosso objetivo é reduzir a quantidade de lixo que é produzido em nossa cidade de São Miguel do Gostoso, localizada no estado do Rio Grande do Norte, Brasil e transformá-lo em produto reciclado. Sendo retirado do lixo comum transformamos em fonte de renda para os coletores e moradores da cidade que fazem parte deste projeto. Precisamos da ajuda de todos, inclusive da sua também e pedimos para que colaborem para que o projeto continue prosseguindo com êxito. Por favor, separem todos os materiais recicláveis, que são: papel, plástico, vidro e metal, do seu lixo produzido, pois semanalmente coletaremos nos comércios dos bairros informados (ASSOCIAÇÃO GOSTOSO RECICLA, s/d)

No entanto, apesar de todos os esforços, a Associação, desde o início das atividades, não alcançou um ponto de equilíbrio minimamente satisfatório para os catadores. De acordo com a Direção da Associação, em resposta ao questionário aplicado, quanto à arrecadação, "os valores são irrisórios, não garante o salário mínimo dos catadores". E complementa, que não consegue "ampliar mais dias de rota, devido não ter recurso para cobrir essa despesa, assim não conseguindo chegar com o projeto em todas as residências de São Miguel do Gostoso".

Efetivamente, quando analisado os dados do questionário (vide Apêndice 1), os números são extremamente baixos, como atestam as respostas oferecidas para o período de janeiro a outubro de 2017:

- $41.129,8 \mathrm{~kg}$ coletados;

- 86 pontos de coleta;

- Média mensal de $4.113,0 \mathrm{~kg}$ coletados; e

- 2 coletas por semana;

Cada ponto de coleta "renderia" apenas $6 \mathrm{~kg}$ : 4.113,0 kg por mês divididos por 86 pontos de coleta, com retirada de material 8 vezes por mês.

Quando estes dados são convertidos monetariamente, a receita média mensal indicada pela Associação foi de $\mathrm{R} \$ 1.057,90$. No final de 2017 estavam registrados 4 catadores; isto representaria - em média - uma receita muito inferior a $R \$ 250,00 /$ mês, pois do valor da venda há se de descontar despesas administrativas, com combustível etc. e, ainda, eventual "remuneração" da pessoa responsável pela administração da Associação.

Apesar da ideia conceitualmente de grande relevância para o meio ambiente vivenciado pela população em São Miguel do Gostoso, a persistir tal 
nível de retribuição pelo trabalho realizado pelos catadores da Associação, há poucas possibilidades de continuidade das atividades ao longo de 2018 se não houver uma participação mais efetiva do poder público, um envolvimento maior das pousadas e hotéis da cidade, além da contribuição permanente de todos (Figura 6). Financeiramente e economicamente, como bem reconhece a Associação, uma das principais dificuldades é justamente a de "manter o projeto em atividade".

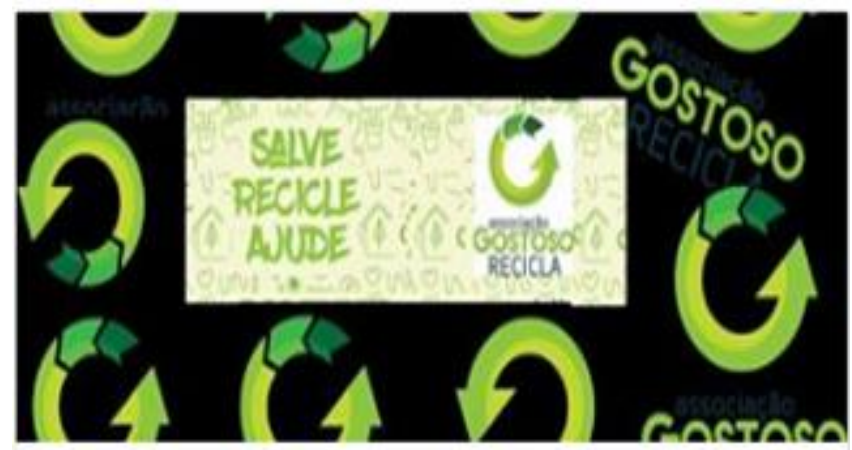

Figura 6: Apresemtação visual da Associação Gostoso Recicla em sua página do Facebook em "Nossa história". Fonte: Associação Gostoso Recicla.

A Associação que adota como missão a salutar ideia de "destinar os recicláveis produzidos na cidade, evitando que eles sejam destinados ao lixão e fazer com que ele retorne para a linha de produção", pretende em 2018 firmar parcerias com a Prefeitura para fortalecer suas ações; mas, não houve, no primeiro quadrimestre, ainda a formalização da parceria.

\section{O projeto de ampliação em Gostoso}

A Associação Gostoso Recicla já adquiriu experiência suficiente para compreender a dinâmica necessária à operacionalização da coleta do lixo em Gostoso e da separação ou reciclagem, bem como compreendeu a dinâmica do mercado para que a receita com a venda direta (ou via intermediário) possa tornar a atividade rentável minimamente ou até mesmo lucrativa e que permita novos (re)investimentos.

Se o aprendizado da operacionalização foi sendo aperfeiçoado diariamente tendo em vista que, essencialmente, dependia de atos internos, tais gestão de pessoas, dos espaços, definição de datas de coleta, de roteiros etc., o que permitiria até mesmo a Associação pensar em possibilidade de eventual expansão, não se pode concluir a mesma trajetória favorável no tocante ao faturamento e rentabilidade do negócio reciclagem.

O mercado da reciclagem, em menor escala, baseada na coleta seletiva de cidades de pequeno porte, como é o caso de São Miguel do Gostoso, depende de dois fatores básicos: de um lado o comprador, com o preço oferecido na compra do material, e do outro lado a quantidade de matéria-prima recolhida e separada (por tipo de lixo: papel, plástico, metal, vidro etc.). Ao longo dos meses de funcionamento da Associação o gargalo, 
como foi relatado em entrevista-questionário com sua diretoria, está justamente na quantidade, no volume resgatado para ser comercializado. Os custos operacionais, por exemplo, para fazer o roteiro do veículo de coleta estão centrados no mesmo item, o combustível mas, o resultado final somente será lucrativo se quantidade de lixo trazido para a sede da Associação for elevada; em outras palavras, um percurso de $10 \mathrm{~km}$, por exemplo, terá um custo " $x$ ", em reais, de combustível e o veículo utilizado poderá recolher apenas 50, 100 ou $200 \mathrm{~kg}$. A receita é variável, mas a despesa, fixa.

Para aumentar o resultado da Associação, isto é, o lixo coletado para reciclagem há duas possibilidades: aumentar o percurso ou aumentar a quantidade coletada. Aumentar o percurso não significará, necessariamente melhor rentabilidade, pois o problema de pouco volume poderá permanecer; mas, aumentar a quantidade terá sempre um melhor resultado.

Consequentemente, para a Associação o ideal é fazer o menor percurso para um maior volume de lixo coletado. Mas, como a quantidade de lixo descartado não pode, certamente, ser antecipada pela Associação, ela estará sempre dependendo de "parcerias", sejam diretas ou indiretas: ações com apoio da prefeitura e do setor hoteleiro, de forma direta e direcionada, ou maior conscientização da população residente ou pendular.

O foco das atenções para o aumento da quantidade de matéria-prima para a Associação passa por ações de Educação Ambiental principalmente com parceiros estratégicos: a prefeitura, a população local, as pousadas/hotéis e os turistas. Para alcançar estes diferentes públicos o projeto proposto envolveria as seguintes ações:

- Prefeitura. Acordo de cooperação para que a prefeitura instale maior quantidade de pontos de coleta seletiva (separados por material) mas também nas escolas, nas ruas de maior circulação, na orla e próximo às principais pousadas e hotéis para que estes empreendedores tenham maior facilidade para descartar o lixo separado, sem precisar "estocá-lo" nos seus estabelecimentos; a Prefeitura poderia também patrocinar publicidade na mídia local (rádio e blog) orientando a prática da coleta seletiva e a responsabilidade de cada cidadão;

- População local. Distribuição de folheteria contendo orientação sobre a separação do lixo doméstico e sobre os pontos de coleta espalhados na cidade bem como o calendário (dias e turnos) em que os veículos da Associação passarão recolhendo o lixo separado;

- Turistas. Elaboração de folheteria para distribuição nas pousadas e hotéis valorizando a necessidade da preservação da natureza em São Miguel do Gostoso (um dos motivos da estada na cidade), apresentando a Associação e sua ação social e solicitando a participação de todos nestas ações; e

- Pousadas e hotéis. Reuniões com os empresários locais para que a Associação conscientize da necessária participação de todos, indicando os pontos de coleta seletiva disponibilizados pela Prefeitura e, em função do volume separado, criação de rota exclusiva para algumas pousadas e hotéis próximos uns aos outros. Uma outra iniciativa seria a criação de uma marca e slogan ("São Miguel do Gostoso: eu protejo a natureza", por Revbea, São Paulo, V. 14, № 1: 295-315, 2019. 
exemplo) que, em uma placa comemorativa, poderia ser distribuída nas pousadas e hotéis que contribuam com a Associação tendo em vista que é - a natureza - um dos atributos prediletos dos turistas, transformando esta ação em um marketing indireto para estes estabelecimentos.

Estas ações devem ocorrer de forma conjunta e coordenada para que o envolvimento de todos possa ser percebido coletivamente e não apenas uma ação pontual, isolada e sem muita repercussão. São ações de baixo custo e com uma visibilidade bastante favorável para todos os envolvidos; sua implantação passa, necessariamente, pelo apoio do poder público municipal, que, considerando a boa prática da gestão das vantagens para seus cidadãos, com estas ações no contexto do meio ambiente terá ainda várias outras vantagens indiretas: qualidade de vida da população, melhoria da paisagem urbana, redução de doenças provocadas pelo acúmulo de lixo, menor nível de despesas com a coleta do lixo, com a saúde etc.

\section{Conclusão}

O lixo urbano é um problema que se agrava em todas as cidades e localidades e que gera um impacto social bastante negativo para todos, sejam as empresas, a população ou o setor público. Reduzir o descarte para lixo é uma proposta que exige ações concretas de todos e que passa, necessariamente, por um processo de conscientização coletiva seja por meio de penalizações (multas, fiscalização ostensiva etc.), seja em ações exclusivamente restritas às prefeituras (regras para o descarte, rotas mais efetivas de coleta do lixo etc.), seja por questões econômicas (processos produtivos mais "limpos", embalagens menos consumidoras de matériasprimas etc.) ou ainda com atitudes comportamentais da população (padrão de consumo, destinação correta do lixo, triagem etc.).

Considerando o perfil socioeconômico de São Miguel do Gostoso a centralidade do problema passa por uma percepção maior de propostas aplicáveis em Educação Ambiental, formais e não-formais, como apresentados, inclusive com ações de baixo impacto econômico e de fácil aplicação a curto e médio prazos. A conscientização da importância da Educação Ambiental é sintomática para que a questão do lixo urbano encontre um amparo à redução de seus impactos sociais.

A Associação Recicla Gostoso surge em um momento especial no município, com a retomada da situação econômica nacional e, consequentemente, maior fluxo de turistas naquele espaço. Certamente, as atividades da Associação não devem ser pautadas exclusivamente em função das vantagens para o turismo e para os turistas, mas sim sob a ótica da necessária atividade em favor de todos; desta forma, qualquer que seja o impacto do turismo na cidade, o projeto beneficiará direta e imediatamente a população local.

Infelizmente, as questões financeiras tornam-se um obstáculo não 
somente para o futuro da Associação como para sua sustentabilidade. Como apresentado pela direção da Associação - e comprovado com os números ora trazidos -, a receita com a coleta e triagem do lixo não tem sido suficiente para assegurar uma renda digna aos catadores da Associação. A ausência de recursos próprios e o reduzido apoio institucional municipal reforçam esta preocupação.

Os esforços empreendidos pela Associação indicam que ainda há áreas de crescimento e oportunidades concretas de realização. A colaboração de todos os envolvidos é peça-chave neste horizonte; uma colaboração que pode nascer e (deve) permanecer quanto maior a transmissão e o reconhecimento da Educação Ambiental como âncora do projeto e da cidadania.

\section{Referências}

ANDRÉ, R. Cooperativa para coleta seletiva é formada em Gostoso. Disponível em: <https://ocontadordecausos.com/2016/12/22/cooperativa-paracoleta-seletiva-e-formada-em-gostoso/>. Acesso em: 22 abr. 2018.

ASSOCIAÇÃO BRASILEIRA DA INDÚSTRIA DE HOTÉIS DO RN/ABIH-RN. Belezas naturais do RN impulsionam turismo e movimentam economia. Disponível em: <http://www.abihrn.com.br/belezas-naturais-do-rn-impulsionamturismo-e-movimentam-economia/>. Acesso em 24 abr. 2018.

ASSOCIAÇÃO GOSTOSO RECICLA. Nossa história. Disponível em: $<$ https://www.facebook.com/pg/gostosorecicla/about/?ref=page internal $>$.

Acesso em: 22 abr. 2018.

BESEN, G.R. Coleta seletiva com inclusão de catadores: construção participativa de indicadores e índices de sustentabilidade. 2011. 275f. Tese (Doutorado em Saúde Pública). Faculdade de Saúde Pública da Universidade Estadual de São Paulo.

BRASIL. Decreto Federal n. 7.404, de 23 de dezembro de 2010. Regulamenta a Lei $\mathrm{n}$ - 12.305, de 2 de agosto de 2010, que institui a Política Nacional de Resíduos Sólidos, cria o Comitê Interministerial da Política Nacional de Resíduos Sólidos e o Comitê Orientador para a Implantação dos Sistemas de Logística Reversa, e dá outras providências. Disponível em: <http://www.planalto.gov.br/ccivil 03/ ato2007-2010/2010/decreto/d7404.htm>. Acesso em: 22 abr. 2018.

BRASIL. Decreto Federal n. 7.405, de 23 de dezembro de 2010. Institui o Programa Pró-Catador, denomina Comitê Interministerial para Inclusão Social e Econômica dos Catadores de Materiais Reutilizáveis e Recicláveis o Comitê Interministerial da Inclusão Social de Catadores de Lixo criado pelo Decreto de 11 de setembro de 2003, dispõe sobre sua organização e funcionamento, e dá outras providências. Disponível em: <http://www.planalto.gov.br/ccivil 03/ ato2007-2010/2010/decreto/d7405.htm>. Acesso em: 22 abr. 2018. 
BRASIL. Ministério do Meio Ambiente. Catadores. Disponível em: <http:// www.mma.gov.br/cidades-sustentaveis/residuos-solidos/catadores-de-materiais -reciclaveis/reciclagem-e-reaproveitamento >. Acesso em: 22 abr. 2018.

BRASIL. Coleta seletiva. Disponível em: <http://www.mma.gov.br/cidadessustentaveis/residuos-solidos/catadores-de-materiais-reciclaveis/reciclagem-ereaproveitamento>. Acesso em: 22 abr. 2018.

BRASIL. Ministério do Turismo. Municípios do RN são agrupados de acordo com o tamanho da economia turística. Disponível em: <http://www.turismo. gov.br/ultimas-noticias/5421-munic\%C3\%ADpios-do-rn-s\%C3\%A3o-agrupados -de-acordo-com-o-tamanho-da-economia-tur\%C3\%ADstica.html>. Acesso em: 24 abr. 2018.

CARDOZO, B.D.A. et al. Estrutura e organização de um empreendimento econômico solidário: um estudo em uma cooperativa de reciclagem. Desafio Online. Campo Grande, v. 5, n. 1, jan.-abr./2017.

CASTRO, R.B.R.; PEREIRA, F.A. Para além da reciclagem: uma proposta extensionista em busca da abordagem crítica da Educação Ambiental. Em Extensão. Uberlândia, v. 15, n. 2, p. 109-125, jul.-dez./2016.

JACOBI, P.R. Educação Ambiental, cidadania e sustentabilidade. Cadernos de Pesquisa. São Paulo, n. 118, p. 189-205, mar./2003.

JACOBI, P.R.; BESEN, G.R. Gestão de resíduos sólidos em São Paulo: desafios e oportunidades. Estudos Avançados. São Paulo, v. 25, n. 71, 2011.

MARCATTO, C. Educação Ambiental: conceitos e princípios. Belo HorizonteMG: Feam, 2002.

MELLO, G.S. et al. Gestão e formação de bens patrimoniais em um empreendimento econômico solidário: um estudo em uma cooperativa de reciclagem. Revista Acadêmica São Marco-RASM. Alvorada, ano 5, n. 2, p. 181-199, jul.-dez./2015.

PALADAR. Gostoso Recicla. Os benefícios da reciclagem em São Miguel do Gostoso. Disponível em: <https://paladarrevista.wordpress.com/2018/04/03 Igostoso-recicla-os-beneficios-da-reciclagem-em-sao-miguel-do-gostoso/>.

Acesso em: 22 abr. 2018.

PORTAL SÃO MIGUEL DO GOSTOSO. A hora do Gostoso. Disponível em: $<$ http://www.oportalsaomigueldogostoso.com.br/pt/a hora do gostoso.html\#ma teria>. Acesso em: 24 abr. 2018.

RODRIGUES, W.; SANTANA, W.C. Análise econômica de sistemas de gestão de resíduos sólidos urbanos: o caso da coleta de lixo seletiva em Palmas, TO. Urbe. Revista Brasileira de Gestão Urbana. Paraná, v. 4, n. 2, p. 299-312, jul.-dez./2012.

SOUZA SILVA, A.R. et al. Impactos ambientais referentes à não coleta de lixo e reciclagem. Ciências Exatas e Tecnológicas. Maceió, v. 2, n. 3, p. 63-76, maio/2015. 


\section{Apêndice 1 - Questionário aplicado com a Associação Gostoso Recicla}

RAZÃO SOCIAL: ASSOCIACÃO DE CATADORES DE MATERIAIS RECICLÁVEIS DE SÃO MIGUEL DO GOSTOSO RN

NOME DE FANTASIA: GOSTOSO RECICLA

DATA (ANO) DE FUNDAÇÃO: Projeto 19/12/2016, Associação em fevereiro/2017

\section{QUADRO DE COLABORADORES}

\begin{tabular}{|c|c|c|}
\hline ATRIBUIÇÕES & $\begin{array}{c}\text { PESSOAS EM } \\
31 / 12 / 2016 \\
\end{array}$ & $\begin{array}{c}\text { PESSOAS EM } \\
31 / 12 / 2017 \\
\end{array}$ \\
\hline 1.1 GERENCIAL & 1 & 1 \\
\hline 1.2 CATADOR/TRIAGEM & 7 & 4 \\
\hline TOTAL & 8 & 5 \\
\hline
\end{tabular}

2. PRINCIPAIS PONTOS DE COLETA (POR ORDEM DE IMPORTÂNCIA):

(Resposta inválida).

3. DISTRIBUIÇÃO DOS PONTOS DE COLETA:

\begin{tabular}{|l|c|}
\hline \multicolumn{1}{|c|}{ LOCALIZAÇÃO (BAIRRO, COMUNIDADE, PRAIA ETC) } & $\begin{array}{c}\text { QTE DE } \\
\text { PONTOS DE } \\
\text { COLETA }\end{array}$ \\
\hline $\begin{array}{l}\text { Ponta do Santo Cristo, Cardeiro, av. principal (Pórtico a mar de Estrela) e } \\
\text { rua dos Dourados }\end{array}$ & 36 \\
\hline $\begin{array}{l}\text { Avenida dos Arrecifes (inicia próximo ao Centro de Cultura), Maceió, rua } \\
\text { dos Búzios }\end{array}$ & 50 \\
\hline TOTAL & 86 \\
\hline
\end{tabular}

4. TIPOS E VOLUME DE MATERIAL COLETADO

\begin{tabular}{|c|c|}
\hline PRODUTO COLETADO & $\begin{array}{c}\text { KG COLETADOS } \\
\text { EM } 2017\end{array}$ \\
\hline 4.1 PAPELÃO/PAPEL & $19.747,0$ \\
\hline 4.2 PLÁSTICO & $7.581,1$ \\
\hline 4.3 VIDRO & $12.419,1$ \\
\hline 4.4 METAL & $1.382,6$ \\
\hline TOTAL & $41.129,8$ \\
\hline
\end{tabular}

5. VALOR ARRECADADO

\begin{tabular}{|l|c|}
\hline \multicolumn{1}{|c|}{ PRODUTO COLETADO } & $\begin{array}{c}\text { VALOR R } \$ \\
\text { EM 2017 }\end{array}$ \\
\hline 5.1 PAPELÃO/PAPEL & $3.866,00$ \\
\hline 5.2 PLÁSTICO & $3.536,00$ \\
\hline 5.3 VIDRO & 940,00 \\
\hline 5.4 METAL TOTAL & $2.237,00$ \\
\hline & $10.579,00$ \\
\hline
\end{tabular}

"Dados correspondem de janeiro a outubro de 2017. Ainda estamos atualizando a planilha".

6. DESTINAÇÃO DAS VENDAS (CIDADE)

\begin{tabular}{|l|l|}
\hline \multicolumn{1}{|c|}{ PRODUTO VENDIDO } & \multicolumn{1}{c|}{$\begin{array}{c}\text { DESTINO } \\
\text { (CIDADE) }\end{array}$} \\
\hline 6.1 PAPELÃO/PAPEL & Natal \\
\hline 6.2 PLÁSTICO & Rio do Fogo \\
\hline 6.3 VIDRO & Natal \\
\hline 6.5 METAL & Rio do Fogo \\
\hline 6.6 ALUMÍNIO & Rio do Fogo \\
\hline
\end{tabular}




\section{LOGÍSTICA DA COLETA (QTE DE VEÍCULOS):}

7.1 CAMINHONETE: $\underline{\text { um }}$

8. DIAS DE COLETA:

( ) Todos os dias, incluindo sábado e domingo

( ) Todos os dias, de segunda a sexta

( ) 1 dia por semana ( $X$ ) 2 dias por semana ( ) 3 dias por semana ( ) 4 dias por semana

9. QUANTIDADE DE MATERIAL COLETADO EXISTENTE NA ASSOCIAÇÃO HOJE:

(A Associação não tem estes dados disponíveis)

10. PREÇO MÉDIO DE VENDA

\begin{tabular}{|l|c|}
\hline \multicolumn{1}{|c|}{ PRODUTO COLETADO } & $\mathrm{KG} / \mathrm{R} \$$ \\
\hline 10.1 PAPELÃO & 0,22 \\
\hline 10.2 PLÁSTICO PET & 0,60 \\
\hline 10.3 VIDRO & 0,15 \\
\hline 10.4 COBRE & 13,00 \\
\hline 10.5 ALUMÍNIO & 4,00 \\
\hline 10.6 PLÁSTICO FILME & 0,70 \\
\hline 10.7 PLÁTICO GROSSO & 0,40 \\
\hline 10.8 FERRO & 0,10 \\
\hline 10.9 LATA/ALUMÍNIO & 3,20 \\
\hline 10.10 PAPEL & 0,15 \\
\hline
\end{tabular}

11. PARCERIAS EM EXECUÇÃO

\begin{tabular}{|l|c|c|c|}
\hline \multicolumn{1}{|c|}{ PARCERIA } & $\begin{array}{c}\text { INÍCIO } \\
\text { (ANO) }\end{array}$ & $\begin{array}{c}\text { FINAL } \\
\text { (ANO) }\end{array}$ & OBJETIVO \\
\hline 11.1 COM A PREFEITURA & --- & --- & Não há parcerias \\
\hline 11.2 COM O ESTADO & --- & --- & Não há parcerias \\
\hline 11.3 COM A UNIÃO & --- & --- & Não há parcerias \\
\hline 11.4 COM OUTRAS ENTIDADES & --- & --- & Não há parcerias \\
\hline
\end{tabular}

12. PRINCIPAIS DIFICULDADES-DESAFIOS PARA A ASSOCIAÇÃO:

"Manter o projeto em atividade, pois atualmente não temos parceria com os órgãos públicos, assim dependendo exclusivamente da venda do material coletado, no entando, os valores são irrisórios, não garante o salário mínimo dos catadores. Outra dificuldade é o espaço que hoje já é insuficiente para a atividade. Não conseguir ampliar mais dias de rota, devido não ter recurso para cobrir essa despesa, assim não conseguindo chegar com 0 projeto em todas as residências de são Miguel do Gostoso."

13. PRINCIPAIS FACILIDADES PARA A ASSOCIAÇÃO: (Sem resposta)

14. PROJETOS \& NOVA AÇÕES PREVISTOS PARA 2018: 'Contrato com a prefeitura.”

15. PROJETOS \& NOVA AÇÕES PREVISTOS PARA 2023: (Sem resposta)

16. MISSÃO DA ASSOCIAÇÃO:

"Destinar os reciclavéis produzidos na cidade, evitando que eles sejam destinados ao lixão e fazer com que ele retorne para a linha de produção."

17. VALORES DA ASSOCIAÇÃO:

"Respeito ao meio ambiente, as pessoas, viventes e ao planeta. Busca em construir um mundo melhor sem lixo."

18. VISÃO DE FUTURO DA ASSOCIAÇÃO: (Sem resposta)

Revbea, São Paulo, V. 14, № 1: 295-315, 2019.

revista brasileira educação ambiental 